\title{
Traumatic Elbow Arthrotomy Pediatric Case Report: The Saline Load Test is a Reliable Method of Detection
}

\author{
Tyler D. Kupchick ${ }^{1}$, Jacob Carl ${ }^{1}$, Eric Wall ${ }^{1}$ \\ Learning Point of the Article: \\ The saline load test is a reliable method to detect a traumatic elbow arthrotomy both in pediatric and adult patients.
}

\section{Abstract}

Introduction: Lacerations and open elbow injuries are common emergency department visits which necessitate an orthopedic surgery evaluation for a traumatic elbow arthrotomy (TEA). A delay in this diagnosis can lead to septic arthritis, requiring more invasive surgical procedures, prolonged antibiotics, and possible long-term sequelae. To date, there is scarce literature on TEA. The purpose of this case report is to better educate the orthopedic community on a reliable method of detection for a TEA, including pediatric patients.

Case Report: Case 1 - Twelve-year-old boy sustained a traumatic dog bite to the right elbow by a large stray dog. Evaluation in the emergency department revealed five 1 centimeter or smaller lacerations over the lateral elbow and another $1 \mathrm{~cm}$ laceration to the volar and proximal forearm. A saline load test (SLT) was performed from a posterior approach and was positive after $20 \mathrm{cc}$ of normal saline was injected into the joint. An arthroscopic irrigation and debridement were performed as definitive treatment. He was discharged with Augmentin BID for 7 days. Follow-up appointments at 1 and 4 weeks post-operatively revealed no signs of infection.

Case 2 - Seven-year-old boy who was in a bicycle accident and sustained a large laceration over the posterior elbow. Evaluation in the emergency department revealed an approximately 15 by $4 \mathrm{~cm}$ laceration over the posterior elbow. A SLT was positive after 30cc's was injected from the anterolateral approach. He underwent arthroscopic irrigation and debridement as definitive treatment and was discharged home with Cephalexin BID for 7 days. Follow-up appointments at 1 and 4 weeks post-operatively showed no signs of infection.

Conclusion: Performing a SLT is a reliable method of detection to evaluate for a TEA. Our case report demonstrated confirmation of TEA in two pediatric patients based on positive SLT. We were able to treat these injuries appropriately with early surgical intervention and prophylactic antibiotics. Our early diagnosis and time-sensitive management prevented septic arthritis based on the patient's short-term follow-up examinations.

Keywords: Traumatic arthrotomy, saline load test, computed tomography scan.

\section{Introduction}

In 2009, the National Electronic Injury Surveillance System (NEISS) reported 92,601 upper extremity injuries with $10.5 \%$ to the elbow [15]. This database includes 100 hospitals pooled together by the United States Consumer Product Safety Commission. The $10.5 \%$ reported in 2009 can then be extrapolated using the CPSC algorithm to 364,245 elbow injuries for the whole United States. In 2019, the NEISS database reported 9577 elbow injuries, which extrapolates to
405, 910 in the United States. Elbow injuries are common reasons for emergency room visits, especially in the pediatric population. Usually, these visits are due to contusions, abrasions, or fractures of the distal humerus, proximal radius, or ulna. Lacerations and open injuries to the elbow are also among these reasons which frequently necessitate an orthopedic surgery evaluation for a traumatic elbow arthrotomy (TEA).

The elbow is a complex joint that is both superficial and deep in relation to the overlying soft tissue. Therefore, any laceration

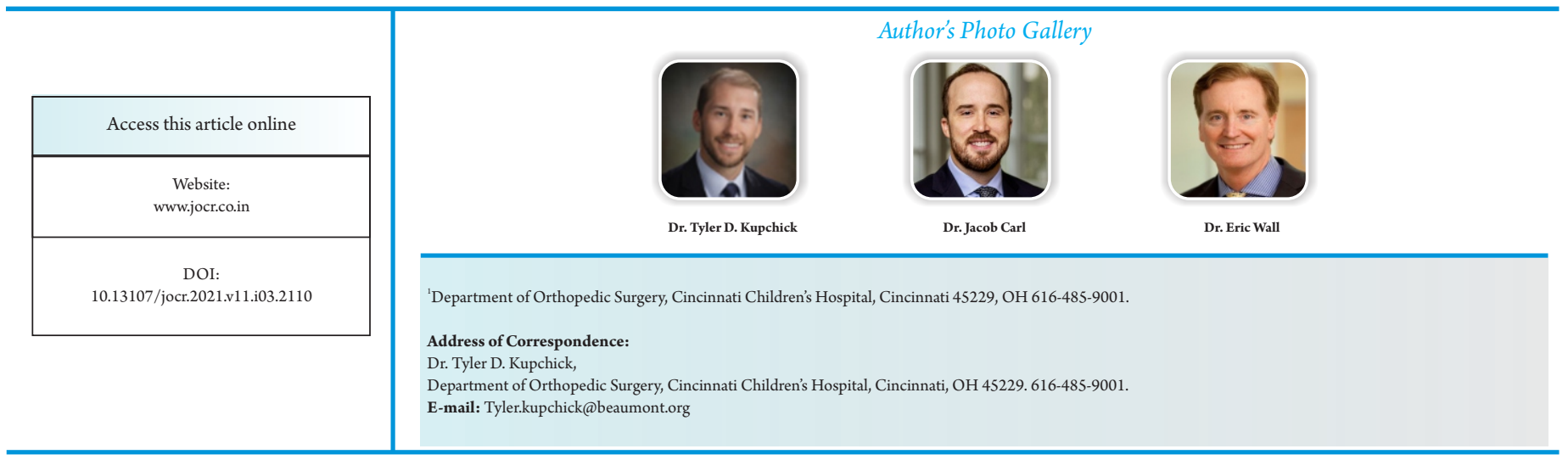

Journal of Orthopaedic Case Reports | pISSN 2250-0685 | eISSN 2321-3817 | Available on www.jocr.co.in | doi:10.13107/jocr.2021.v11.i03.2110 This is an Open Access article distributed under the terms of the Creative Commons Attribution Non-Commercial License (http://creativecommons.org/licenses/by-nc/3.0) which permits unrestricted non-commercial use, distribution, and reproduction in any medium, provided the original work is properly cited. 

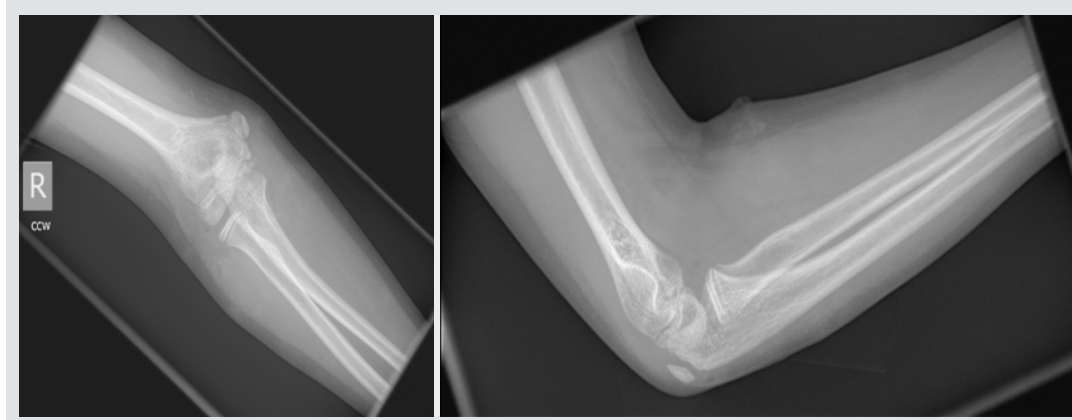

Figure 1: Anterior-posterior, lateral, and oblique X-rays of the right elbow in Case 1 demonstrating soft tissue injury, however, no fracture, dislocation, or intra-articular air.

around the elbow needs to be evaluated for a traumatic arthrotomy. A diligent physical examination of the injured extremity is required yet may not be enough to identify disruption of the joint capsule, i.e., traumatic arthrotomy $[2,6$, $7,8,12,14]$. An open arthrotomy can seed bacteria from the skin or environment into the joint and develop into septic arthritis $[1,5,16]$. Bacteria recruit inflammatory cytokines which produce chondrolytic enzymes that destroy the cartilage within 1 week $[1,5,16]$. A delay in this diagnosis has been seen in up to $11.8 \%$ of traumatic arthrotomy of the knee (TAK) [ 5 , 11] and will require more invasive surgical procedures and prolonged antibiotics $[1,2,5,16]$. Conventionally, a traumatic arthrotomy is evaluated with either a saline load test (SLT) or computed tomography (CT) scan. A SLT is performed by injecting fluid into a joint, remote from the injury site. Extravasation of the fluid from the injury site yields a positive test. CT scan has been historically used to diagnose traumatic arthrotomy by evaluating for intra-articular air. Kupchick et al.12 performed a cadaveric study on 10 specimens comparing CT scan to SLT and found the SLT to be the more sensitive method of TEA detection. Feathers et al. [6] also performed a SLT cadaveric study on 36 specimens demonstrating a $95 \%$ sensitivity after $40 \mathrm{mLs}$ of fluid injected. The best method of detection for the elbow, however, remains unclear as most of the literature regarding traumatic arthrotomies references the knee

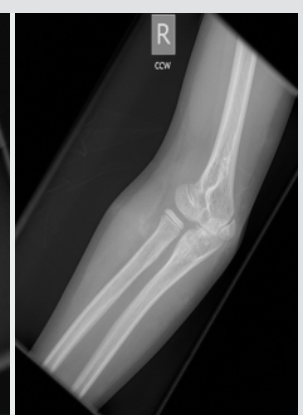

(Table 1).

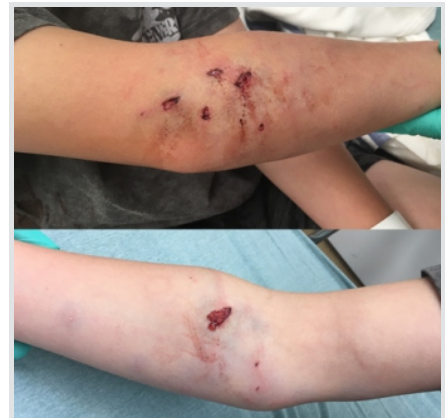

Figure 2: Clinical photographs of Case 1 elbow after bit by a stray dog. Five dorsal lacerations and one volarlaceration.
Konda et al. [11] retrospectively observed 63 knee injuries and determined CT scans as the more accurate method of detection for TAK ( $100 \%$ sensitivity) over a SLT (92\% sensitivity). Keese et al. [10] and Nord et al. [13] each studied SLT of the knee and found $95 \%$ sensitivity after 194 and $155 \mathrm{~mL}$ of normal saline were injected, respectively. To date, there is scarce literature on non-cadaveric TEA, let alone the pediatric population. The purpose of this case report is to better educate the orthopedic community on the reliability of a SLT to detect a TEA, including the pediatric patient.

\section{Methods}

After approval from our institutional review board, we referenced two pediatric patients ( 12 and 7 years old) with open elbow injuries. Inclusion criteria consisted of open elbow injuries without any obvious physical examination findings of TEA or any intra-articular air seen on X-ray. Diagnosis of a TEA was made with a positive SLT in the emergency department. Each patient underwent an arthroscopic irrigation and debridement with a short course of oral antibiotics. On shortterm follow-up, neither child had any signs or symptoms of an infection or septicjoint.

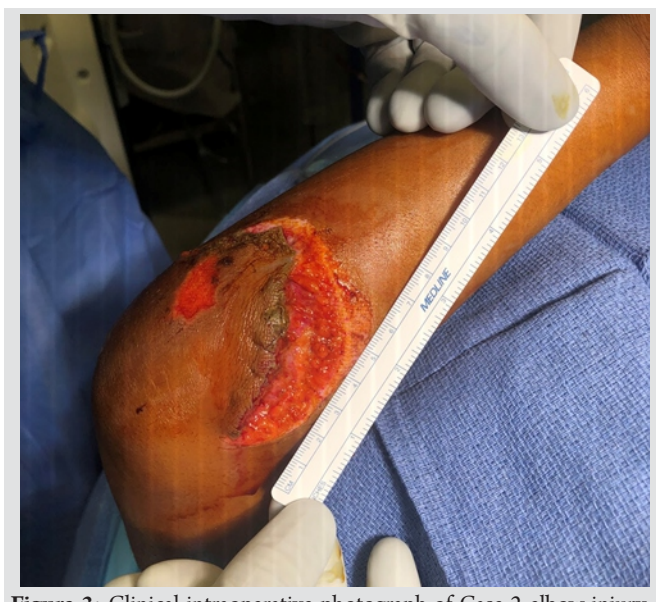

Figure 3: Clinical intraoperative photograph of Case 2 elbow injury. The laceration measured $15 \mathrm{~cm} \times 4 \mathrm{~cm}$ with large flap over the proximal ulna.
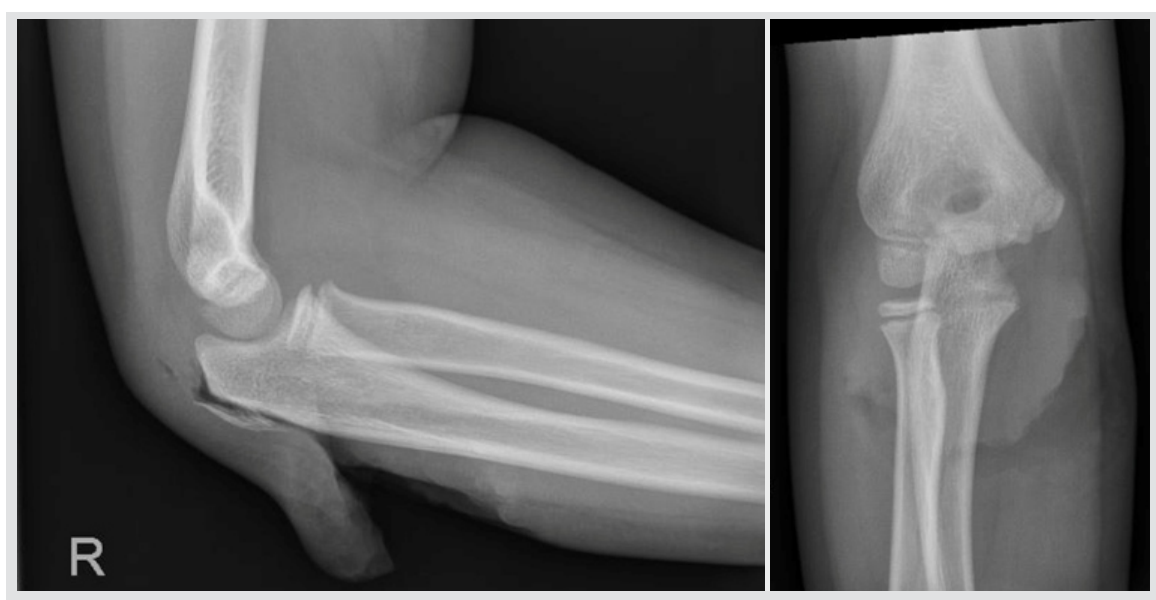

Figure 4: Anterior-posterior and lateral elbow X-rays of Case 2 demonstrating a large soft tissue injury to the posterior, proximal ulna, however, no fracture, dislocation, or intra-articular air. 


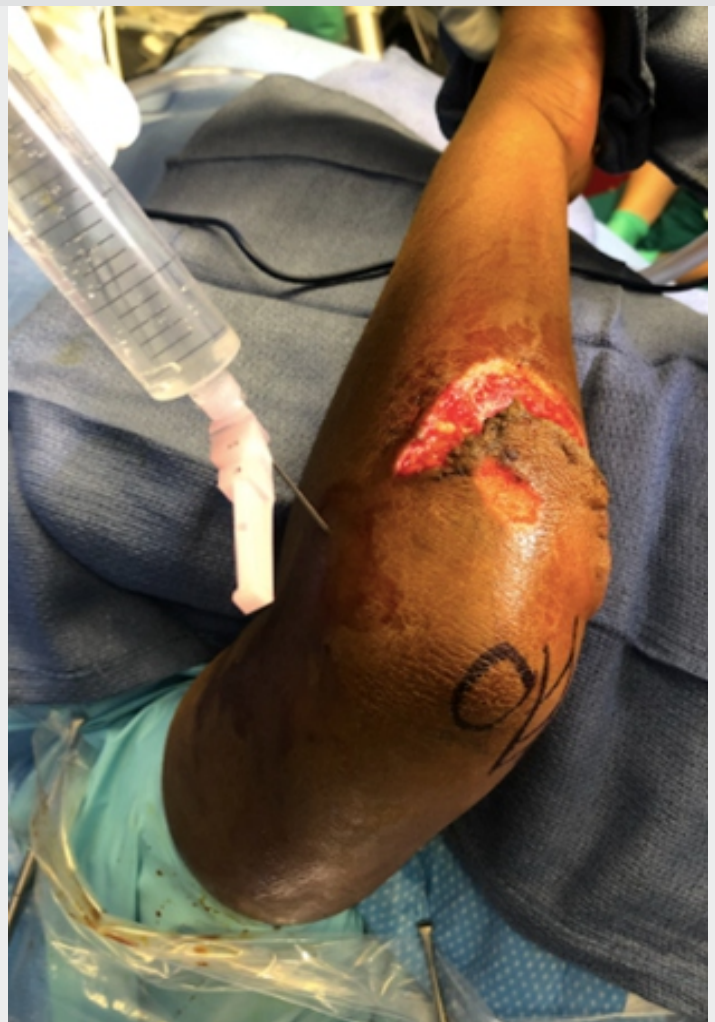

Figure 5: Clinical intraoperative photograph of Case 2 demonstrating the saline load test technique used to diagnose a traumatic elbow arthrotomy. The needle was inserted into the anterolateral "soft spot" arthroscopic portal.

\section{Case Report}

Case \# 1 - Twelve-year-old Caucasian boy sustained a traumatic dog bite to the right elbow by a large stray dog and was brought to an outside hospital. X-rays were performed and reported no fracture, dislocation, or intra-articular air (Fig. 1).

The elbow wounds were irrigated with normal saline and bathed in a normal saline/betadine mixed solution for $15 \mathrm{~min}$ at this outside facility. The patient was given Augmentin as well as rabies immunoglobulin and vaccine due to the unknown canine vaccination history. $\mathrm{He}$ was then transferred to our tertiary children's hospital for further orthopedic surgery evaluation. Evaluation in the emergency department revealed five $1 \mathrm{~cm}$ or smaller lacerations over the lateral elbow and another $1 \mathrm{~cm}$ laceration to the volar and proximal forearm, just distal to the antecubital fossa (Fig. 2).

The patient had near full range of motion, falling about 10 degrees shy of full extension and 10 degrees short of full supination, limited by pain. He was also found to be grossly neurovascularly intact of the median, radial, and ulnar nerves to motor and sensation with strong radial and ulnar pulses. A SLT was performed through the posterior arthroscopic portal site into the olecranon fossa [4]. Fluid was seen extravasating from the lateral elbow wounds once $20 \mathrm{cc}$ of normal saline was injected into the joint, thus a positive test. He was admitted overnight for continued antibiotics (Augmentin 875-125 mg every $8 \mathrm{~h}$ ) and surgical arthroscopic irrigation and debridement the next morning. For the procedure, the patient was positioned supine with the elbow across the chest. The posterior arthroscopic portal was established as well as the anterolateral arthroscopic portal with $2.7 \mathrm{~mm}$ cannulas [4]. Three liters of normal saline irrigation were run through the joint and all the wounds with gentle curettage debridement. The wounds were then loosely closed, and a sterile dressing with a long arm splint was applied without a drain to allow soft tissue rest. He was discharged with Augmentin 400/57mg/5 mL BID prophylactically for 7 days. The patient followed up in the office 1-week and 4-week post-operatively. He was without any erythema, drainage, or signs of infection; however, mild elbow stiffness in extension had improved.

Case \#2 - Seven-year-old African American boy was in a bicycle accident and sustained a large laceration over the proximal ulna/posterior elbow. Evaluation in the emergency department revealed an approximately 15 by $4 \mathrm{~cm}$ "U" like laceration with a large flap over the posterior elbow/proximal ulna (Fig. 3).

Subcutaneous tissue, muscle, and triceps tendon were visualized, however, no obvious joint capsule violation. The patient had near full range of motion, about 10 degrees shy of full flexion and extension limited by pain. He was grossly neurovascularly intact of the median, radial, and ulnar nerves to motor and sensation with strong radial and ulnar pulses. X-ray revealed posterior elbow soft tissue injury and no intra-articular air (Fig. 4).

A small bony fragment was displaced from the posterior aspect of the proximal ulna. A SLT was performed through the anterolateral "soft spot" arthroscopic portal site4, and fluid was seen extravasating from the wound after $30 \mathrm{cc}$ of normal saline was injected (Fig. 5).

He was admitted overnight for continued antibiotics (IV Ancef $40 \mathrm{mg} / \mathrm{mL}$ every $8 \mathrm{~h}$ ) and surgical arthroscopic irrigation and debridement the next morning. For the procedure, the patient was positioned supine with the elbow across the chest. The posterior arthroscopic portal was established as well as the anterolateral arthroscopic portal with $2.7 \mathrm{~mm}$ cannulas [4]. Three liters of normal saline irrigation were run through the joint and the wound with gentle curettage debridement. The small bony fragment was deemed non-viable and excised. The wound was then loosely closed, and a sterile dressing with a long arm splint was applied without a drain to allow soft tissue rest. He was discharged home with Cephalexin $500 \mathrm{mg}$ BID prophylactically for 7 days. The patient followed up in the office 1-week and 4-week post-operatively without any erythema, drainage, or signs of infection and had near full elbow range of motion. 
A traumatic arthrotomy is a challenging diagnosis, particularly of a dynamic joint such as the elbow. The elbow has areas with minimal soft tissue overlying the joint and other areas where the laceration must penetrate much deeper. As the elbow flexes, extends, pronates, and supinates, the subcutaneous tissue glides over the muscles and fascia. This could potentially hide any capsular disruptions and trap debris. This case report demonstrated two different open elbow injuries in children which both cases confirmed a positive TEA with a SLT. The volume of fluid injected to reach a positive test, 20 and $30 \mathrm{mLs}$, is consistent with the findings of Feathers and Kupchick. Each patient was then able to undergo minor surgical intervention of irrigation and debridement with a short course of prophylactic oral antibiotics to prevent a deep infection or septic joint. Per our literature review (Table 1), most TEA detection literature references cadaveric studies $[6,12]$ and only one human case report [3]. In general, the majority of traumatic arthrotomy literature pertains to the knee, which has demonstrated unparalleled results to the elbow and may cloud the judgment of TEA detection method. In addition, there have been no studies of TEA in the pediatric population. For this reason, there is no clear recommendation on the detection of a TEA.

Table 1: Literature review of traumatic arthrotomies

\begin{tabular}{|c|c|c|c|c|c|}
\hline Author & Year & Study & Journal & Body Region & Results \\
\hline Feathers T, et al. & 2011 & $\begin{array}{l}\text { Effectiveness of the saline load test in } \\
\text { diagnosis of traumatic elbow arthrotomies }\end{array}$ & J Trauma & Ebow & $\begin{array}{l}36 \text { cadaveric specimens with controlled posterior } \\
\text { arthrotomy. SLT performed with methylene blue. } \\
40 \mathrm{~mL} \text { 's of fluid needed for } 95 \% \text { sensitivity }\end{array}$ \\
\hline Kupchick T, et al. & 2020 & $\begin{array}{l}\text { Detection of traumatic elbow arthrotomies: } \\
\text { CT scan vs saline load test }\end{array}$ & J Shoulder Ebow Surg & 日bow & $\begin{array}{l}10 \text { cadaveric specimens with controlled posterior } \\
\text { arthrotomy. CT scan then SLT performed. To reach } 60 \\
\text { and } 90 \% \text { sensitivity, } 15 \text { and } 20 \text { mL's of fluid needed to } \\
\text { be injected. Positive tests noted after average injection } \\
\text { of } 19 \mathrm{~mL} \text { 's. CT scan } 0 \% \text { sensitivity. }\end{array}$ \\
\hline Bunyasaranand $\mathrm{J}$, et al & 2017 & $\begin{array}{l}\text { Case report: traumatic el bow arthrotomy } \\
\text { after motorcycle accident not evident on CT }\end{array}$ & BMN Case Report & Ebow & $\begin{array}{c}\text { One patient with } 6 \mathrm{~cm} \text { elbow laceration from MCA CT } \\
\text { scan was negative for intra-articular air. Pesented } \\
\text { with signs of septic joint. Nb SLT performed at } \\
\text { presentation. }\end{array}$ \\
\hline Konda S, et al. & 2013 & $\begin{array}{l}\text { The saline load test of the knee redefined: a } \\
\text { test to detect traumatic arthrotomies and rule } \\
\text { out periarticular wounds not requiring } \\
\text { surgical intervention }\end{array}$ & J Othop Trauma & Knee & $\begin{array}{l}50 \text { patients tested with SLT. There were } 19 \text { positive } \\
\text { SLTs; } 16 \text { true positive TAK, and } 3 \text { false positive TAK of } \\
\text { the } 31 \text { negative SLTs, only } 1 \text { was a false negative. } \\
\text { Average volume injected } 75+/-28 \mathrm{~mL} \text {. SLT sensitivity } \\
\text { and specificity of } 94 \text { and } 91 \% \text {. }\end{array}$ \\
\hline Konda S, et al. & 2013 & $\begin{array}{l}\text { Computed tomography scan to detect } \\
\text { traumatic arthrotomies and identify } \\
\text { periarticular words not requiring surgical } \\
\text { intervention: An improvement over saline } \\
\text { load test }\end{array}$ & J Othop Trauma & Knee & $\begin{array}{c}63 \text { knee's were evaluated for TAK with CT scan in the } \\
\text { DD. Al } 32 \text { knees with intra-articular air on CT had CR } \\
\text { confirmation ( } 100 \% \text { sensitivity), and none of the } 31 \\
\text { negative CT's presented with knee infection at follow } \\
\text { up. } 37 \text { knees underwent both CT and SLT, where the } \\
\text { SLT sensitivity was } 92 \%\end{array}$ \\
\hline Nord R, et al. & 2009 & $\begin{array}{l}\text { Detection of traumatic arthrotomy of the knee } \\
\text { using the saline solution load test }\end{array}$ & J Bone Joint Surg & Knee & $\begin{array}{c}56 \text { patients with controlled knee arthrotomies in the OR } \\
\text { for arthroscopy portal sites, evaluated with saline load } \\
\text { tests. } 75,110,145,155,175 \mathrm{~mL} \text { of fluid needed for } 50 \text {, } \\
75,90,95,99 \% \text { sensitivity. Average positive SLT was } \\
64 \text { and } 95 \mathrm{~mL} \text { 's for the inferomedial and superomedial } \\
\text { injection locations }\end{array}$ \\
\hline Keese, et al & 2007 & $\begin{array}{c}\text { The accuracy of the saline load retention test } \\
\text { in the diagnosis of traumatic knee } \\
\text { arthrotomies }\end{array}$ & J Othop Trauma & Knee & $\begin{array}{l}30 \text { patients with controlled knee arthrotomies in the CR } \\
\text { for arthroscopy portal sites, evaluated with saline load } \\
\text { tests. } 50 \text { and } 194 \mathrm{~mL} \text { 's of fluid needed for } 46 \text { and } 95 \% \\
\text { sensitivity. Average positive SLT was } 71 \mathrm{~mL}\end{array}$ \\
\hline Tornetta P, et al. & 2008 & $\begin{array}{l}\text { How effective is a saline arthrogram for } \\
\text { wounds around the knee? }\end{array}$ & Cin Othop Relat Res & Knee & $\begin{array}{l}80 \text { knees with controlled knee arthrotomies in the CR } \\
\text { for arthroscopy portal sites, evaluated with saline load } \\
\text { tests. Injection of only } 60 \mathrm{~mL} \text { 's performed with } 36 \% \\
\text { static sensitivity, and } 43 \% \text { dynamic sensitivity. }\end{array}$ \\
\hline Voit G et al. & 1996 & $\begin{array}{l}\text { Saline load test for penetration of } \\
\text { periarticular lacerations }\end{array}$ & J Bone Joint Surg & General & $\begin{array}{c}50 \text { patients with peri-articular lacerations evaluated by } \\
\text { clinical exam and saline load test. } 39 \% \text { false positive } \\
\text { and } 43 \% \text { false negative clinical examinations, based } \\
\text { on saline load test results }\end{array}$ \\
\hline Goyal N et al. & 2019 & $\begin{array}{l}\text { Saline load test for detecting traumatic } \\
\text { arthrotomy in the wrist }\end{array}$ & J Wrist Surg & Wist & $\begin{array}{l}20 \text { patients with controlled wrist arthrotomy in CRfor } \\
\text { arthroscopy portal sites, evaluated with saline load } \\
\text { tests. Volume needed for 50, 90, 95, and } 99 \% \\
\text { sensitivities are: } 0.4,2.2,2.3 \text { and } 2.5 \text { mL's }\end{array}$ \\
\hline Gttings D, et al. & 2019 & $\begin{array}{l}\text { Saline load test is effective at diagnosing } \\
\text { traumatic arthrotomies of the shoulder }\end{array}$ & J Surg Othop Adv & Shoulder & $\begin{array}{l}22 \text { cadaveric specimens with controlled posterior } \\
\text { arthroscopic portal arthrotomy. Injection of } 62,81 \text {, and } \\
136 \text { mL's yielded 90, 95, and } 99 \% \text { sensitivities for SLT. }\end{array}$ \\
\hline
\end{tabular}


The normal elbow volume has been estimated to be $10-15 \mathrm{~mL}$ where the maximum capsular volume is about $20-25 \mathrm{mLs}$ [9, 14]. Early on, detection of a traumatic arthrotomy by SLT was the method of choice [18]. Voit et al. [18] demonstrated SLTs higher diagnostic accuracy of traumatic arthrotomies over clinical examination which had a $43 \%$ false-negative and 39\% false-positive rate.

Leading the way for TEA, Feathers et al. [6] performed a SLT on 36 cadaveric elbows and provided sensitivities with the injected fluid amounts. Initially, the specimens were injected with $20 \mathrm{mLs}$ of saline referencing O'Driscoll's et al. elbow capsular capacity [14]. Seventy-two percent of their specimens had a positive SLT at this amount. They found that a total of 40 $\mathrm{mLs}$ were needed to reach a sensitivity of $95 \%$. To incorporate the complexity of the elbow, they demonstrated a static (immobilized) sensitivity of 58-87\% and a dynamic (mobile) sensitivity of $75-97 \%$ after $20 \mathrm{mLs}$ were injected.

Kupchick et al. [12] is the only study to compare SLT with CT scan for TEA. Using 10 cadaveric specimens, they made a controlled arthrotomy and then brought the specimens through full range of motion. Afterward, a non-contrast CT scan was completed. Following this, a SLT was performed with normal saline and methylene blue mixed solution. All of their specimens were positive for the SLT with a 60 and $90 \%$ sensitivity after 15 and $20 \mathrm{mLs}$ of fluid injected, respectively. An average injection of $19 \mathrm{mLs}$ was needed for a positive test. None of the CT scans, however, were positive for intra-articular air (0\% sensitivity).

Konda et al. [11] evaluated 62 patients ( 63 knees) for traumatic arthrotomy of the knee (TAK) with CT scan and SLT. Thirtytwo knees were positive for TAK on CT scan, with OR confirmation of all 32 knees (100\% sensitivity). No patients with a negative CT scan had developed septic arthritis upon follow-up. Thirty seven of the knees had undergone both CT and SLT; however, false positives of the SLT lowered the sensitivity to $92 \%$.

In similar studies from 2007 to 2009, Keese et al. [10] and Nord et al. [13] both performed SLT with controlled knee arthrotomies on patient's scheduled for knee arthroscopy. Keese et al. found 46 and $95 \%$ sensitivity after 50 and 194 mLs of fluid were injected into the knee. Nord et al. went into more detail and found 50,75, 90, 95, and $99 \%$ sensitivity after 75,110 , 145,155 , and $175 \mathrm{~mL}$ 's of fluid were injected. In 2008, Tornetta et al. [17] also performed SLT on knee arthrotomies for scheduled knee arthroscopy. He, however, evaluated a fixed amount of fluid ( $60 \mathrm{~mL}$ 's) for the SLT while bringing the knee through range of motion. They found a static sensitivity at 60 mLs of $36 \%$ and dynamic sensitivity of $43 \%$.

The only case report on TEAs thus far was published by
Bunyasaranand et al. [3]. Their patient sustained a $6 \mathrm{~cm}$ elbow laceration from a motorcycle accident. Examination in the emergency department revealed no obvious capsular violation, and a CT scan was negative for intra-articular air. The patient received a bedside irrigation and wound repair; however, no SLT was performed. The patient presented with signs and symptoms of a septic elbow and purulent drainage at his 1-week follow-up appointment. Two separate irrigation and debridement procedures in the operating room then followed, with an intraoperative confirmed joint capsule laceration. Although only one incident, this case report demonstrates that if we were to follow the traumatic knee arthrotomy recommendations to CT scan the joint (over SLT), we may miss the arthrotomy diagnosis more often than literature suggests.

A systematic review by Browning et al. [2] yields 10 relevant studies on SLTs to evaluate for traumatic arthrotomy. The studies reviewed included Voit and Feathers et al. Their data included SLTs of the knee, elbow, ankle, and wrist. They agreed with the efficacy of SLT and however were inconclusive in the analysis and utility in the clinical setting. They also recommended more joints and pediatric patients to be studied.

\section{Conclusions}

Our case report demonstrated the reliability of a SLT to detect a TEA, even in the pediatric population. The volume of fluid injected to yield a positive SLT was consistent with the literature. We were able to treat these injuries appropriately with early surgical intervention and prophylactic antibiotics. Our early diagnosis and time-sensitive management prevented septic arthritis and further morbidity to these children.

\section{Clinical Message}

The diagnosis of a TEA by a SLT is a reliable method of detection, even in the pediatric population. 


\section{References}

1. Azar FM, Beaty JH, Canale ST. Campbell's Operative Orthopedics. 13th ed. United States: Lippincott Williams \&Wilkins; 2017.p.2662-8.

2. Browning BB, Ventimiglia AV, Dixit A, Illical E, Urban WP, Jauregui JJ. Does the saline load test still have a role in the orthopaedic world? A systematic review of the literature. Acta Orthop Traumatol Turc 2016;50:597-600.

3. Bunyasaranand JC, Foeger NC, Ryan PM. Case report: Traumatic elbow arthrotomy after motorcycle accident not evident on CT. BMJ Case Rep 2017; 2017: bcr201722 1094.

4. Camp CL, Degen RM, Sanchez-Sotelo J, Altchek DW, Dines JS. Basics of elbow arthroscopy Part I: Surface anatomy, portals, and structures at risk. Arthrosc Tech 2016;5: e1339-43.

5. Collins DN, Temple SD. Open joint injuries: Classification and treatment. Clin Orthop Relat Res 1989;243:48-56.

6. Feathers T, Stinner D, Kirk KM, Kirby J, Hsu JR, Skeletal Trauma Research Consortium, et al. Effectiveness of the saline load test in diagnosis of traumatic elbow arthrotomies.J Trauma 2011;71:E110-3.

7. Gittings D, Dattilo J, Fryhofer G, Martin A, Hast M. The saline load test is effective at diagnosing traumatic arthrotomies of the shoulder. J Surg Orthop Adv 2019;28:268-71.

8. Goyal N, Bohl DD, Frank RM, Slikker W 3rd, Fernandez JJ, Cohen MS, et al. Saline load test for detecting traumatic arthrotomy in the wrist.J Wrist Surg 2019;8:221-5.

9. Johansson O. Capsular and ligament injuries of the elbow joint. A clinical and arthrographic study. Acta Chir Scand 1962;287:1-159.

10. Keese GR, Boody AR, Wongworawat MD, Jobe CM. The accuracy of the saline load retention test in the diagnosis of traumatic knee arthrotomies. J Orthop Trauma 2007;21:442-3.

11. Konda SR, Davidovitch RI, Egol KA. Computed tomography scan to detect traumatic arthrotomies and identify periarticular wounds not requiring surgical intervention: An improvement over saline load test. J Orthop Trauma 2013;27:498-504.

12. Kupchick TD, Yousif MJ, Colen AJ, Fenkell BR, Faulkner AM. Detection of traumatic elbow arthrotomies: Computed tomography scan vs saline load test. J Shoulder Elbow Surg 2020;29:1869-75.

13. Nord RM, Quach T, Walsh M, Pereira D, Tejwani NC. Detection of traumatic arthrotomy of the knee using the saline solution load test.J Bone Joint Surg Am 2009;91:6670.

14. O’Driscoll S, Morrey B, Kai-Nan A. Intraarticular pressure and capacity of the elbow. Arthroscopy 1990;6:100-3.

15. Ootes D, Lambers KT, Ring DC. The epidemiology of upper extremity injuries presenting to the emergency department in the United States. Hand (NY) 2012;7:1822.

16. Patzakis MJ, Dorr LD, Ivler D, Moore TM Harvey JP Jr. The early management of open joint injuries. A prospective study of one hundred and forty patients. J Bone Joint Surg Am 1975;57:1065-70.

17. Tornetta P 3rd, Boces MT, Schepsis AA, Foster TE, Bhandari M, Garcia E. How effective is a saline arthrogram for wounds around the knee? Clin Orthop Relat Res 2008;466:432-5.

18. Voit GA, Irvine G, Beals RK. Saline load test for penetration of periarticular lacerations. J Bone Joint Surg Am 1996;78B:732-3.
Conflict of Interest: Nil

Source of Support: Nil

Consent: The authors confirm that informed consent was obtained from the patient for publication of this case report
How to Cite this Article

Kupchick TD, Carl J, Wall E. Traumatic Elbow Arthrotomy Pediatric Case Report: The Saline Load Test is a Reliable Method of Detection. Journal of Orthopaedic Case Reports 2021 March;11(3): 107-112. 